Voix et Images

\title{
Deuxièmes éditions. Poésie et structures sociales / Soljénitsyne ou le salut de l'Histoire
}

\section{Fernand Dumont}

Volume 27, numéro 1 (79), automne 2001

Fernand Dumont

URI : https://id.erudit.org/iderudit/201584ar

DOI : https://doi.org/10.7202/201584ar

Aller au sommaire du numéro

Éditeur(s)

Université du Québec à Montréal

ISSN

0318-9201 (imprimé)

1705-933X (numérique)

Découvrir la revue

Citer cet article

Dumont, F. (2001). Deuxièmes éditions. Poésie et structures sociales / Soljénitsyne ou le salut de l'Histoire. Voix et Images, 27(1), 86-93. https://doi.org/10.7202/201584ar d'utilisation que vous pouvez consulter en ligne.

https://apropos.erudit.org/fr/usagers/politique-dutilisation/ 


\title{
Deuxièmes éditions
}

\section{Poésie et structures sociales ${ }^{1}$}

\author{
Fernand Dumont
}

Le poète Fernand Dumont - auteur de L'ange du matin (éd. de Malte) - a prononcé mardi dernier à la Société d'Étude une remarquable conférence dans laquelle il a voulu définir la poésie moderne par rapport à l'histoire. Il a discerné trois "couches de l'expérience poétique - qui sont, en même temps, les points d'attache de la poésie et du poète dans l'bistoire des bommes":

1) poésie et structures sociales au sens strict - c'est-à-dire possession du monde;

2) poésie et langage - c'est-à-dire recherche d'une communauté par la technique;

3) le poème proprement dit - c'est-à-dire tentative de transcender l'bistoire.

Le texte que nous donnons ci-dessous concerne la poésie et les structures sociales.

\section{$\stackrel{*}{* *}$}

La poésie contemporaine commence par être, à un premier niveau, évaluation des structures sociales au sens strict. C'est en ce sens que la poésie est profondément tentative de possession du monde.

Depuis le milieu du xix ${ }^{e}$ siècle, l'histoire s'est "accélérée" pour reprendre l'expression célèbre de Daniel Halévy. La révolution industrielle et la concentration démographique ont transformé brusquement et radicalement le milieu physique où vivent les hommes. La ville et la machine sont venues non seulement reléguer la charrue, mais aussi le genre pastoral. À cette transformation, les poètes ne sont pas restés insensibles. Les thèmes sont déjà présents chez Rimbaud et Baudelaire. Mais, sur ce point comme bien d'autres, c'est Apollinaire qui a marqué le tournant:

$\grave{A}$ la fin tu es las de ce monde

ancien

1. Publié originalement dans Le Devoir, samedi 31 janvier 1953. L'avant-propos a été rédigé par l'équipe de rédaction du Devoir. 
Bergère ô tour Eiffel le troupeau

$$
\text { des ponts bêle ce matin }
$$

Tu en as assez de vivre dans

l'antiquité grecque et romaine

$\mathrm{Tu}$ lis les prospectus les catalogues

les affiches qui chantent

tout haut

Voilà la poésie ce matin et pour la

prose il y a les journaux

Il y a les livraisons à 25 centimes

pleines d'aventures policières...

Ce qui est très curieux, c'est que les poètes ont été ici des initiateurs; avant les philosophes et les penseurs, ce sont eux qui ont vu d'abord le sens spirituel profond de l'avènement d'une civilisation urbaine. Les premiers, ils l'ont soumis à l'alchimie de leur sensibilité et de leur rêve. Leur attitude a été diverse. Les uns ont traduit une sensibilité fanée par la disparition de la nature, telle qu'elle s'inscrit, par exemple, dans ces vers de Paul Morand:

\section{Sur les pavés}

Où déjà s'établit une lune ovoïde.

Un ciel Magenta demeure décalque parmi

Les tuyaux articulés et les arbres en celluloïd.

D'autres ont continué de rêver, et la ville est devenue un aliment du songe, une nouvelle source de merveilleux. C'est Léon-Paul Fargue qu'il faut ici rappeler:

Un tramway secouait, en frôlant les feuillages,

Son harnais de sommeil dans les flancs des rues.

L'hippocampe roulait sa barque et sa lanterne

Sur les pièges du fer et sur les clefs perdues.

Il y avait un mur assommé de traverses

Avec un bec de gaz tout taché de rousseur

Où fusaient tristement les insectes des arbres

Sous le regard absent des éclairs de chaleur.

Dans le changement des structures sociales, la machine s'est alliée à la croissance proliférante de la ville: dans la poésie aussi. Pour rappeler tous les poètes qui ont fait de la machine un thème poétique, il faudrait aligner ici de nombreux noms. Il suffira d'évoquer cette curieuse école futuriste, d'avant 1914, où se marquait un désir à la fois conscient et naif de s'adapter à un monde de la matière immédiate, en même temps que la volonté violente, et presque aveugle, d'en finir avec un monde du sentiment avec ce que les tenants de l'École nommaient ironiquement les "besoins du cœur" et les "aspirations de l'âme". Poésie de choc un peu monotone, chantant au fond, à travers la volonté de puissance, la peine éternelle des poètes, la perte de l'Éden, qui demeure toujours comme une nostalgie cachée au fond de ce matérialisme poétique. Poésie qui est exactement, au sens rigoureux, celle de l'homme de l'usine, machine liée 
à la machine, rêvant inconsciemment du Paradis perdu à travers la ville illuminée de néon ou les pages de la petite revue américaine.

Civilisation de la machine, de la ville, cette époque est aussi celle du développement prodigieux des voies de communication. Bien avant que les économistes et les sociologues contemporains aient parlé de "l'économie des grands espaces ", la sensibilité des poètes avait donné naissance à un lyrisme planétaire, dont Valéry Larbaud demeure le symbole:

J'ai senti pour la première fois toute la douceur de vivre,

Dans une cabine du Nord-Express, entre Wirballen et Pskow.

Prêtez-moi, ô Orient-Express, Sud-Brennes, prêtez-moi

Vos miraculeux bruits sourds...

Villes, machines, communications multiples: ce ne sont là que les éléments d'un phénomène plus vaste, le monde où nous vivons, celui des masses. Cette synthèse devait être faite, en poésie même, par une école aujourd'hui bien morte: l'unanimisme. Le précurseur, ici, a été Walt Whitman dont je qualifierais volontiers l'œuvre, dans sa majeure partie, de "poésie de la concentration démographique". Larbaud, dans la préface à la traduction française des Poèmes choisis de l'écrivain américain, y voyait justement "un moi cessant de bouder, à l'écart, ou de se soigner, ou de cultiver ses manies, ou de s'adorer, mais vivant en contact avec les autres moi, en masse".

L'unanimisme fera, de cette attitude, un véritable système. Il faut y voir une tentative de création d'un genre épique moderne, où deux tendances s'entremêlent confusément : le désir de la possession charnelle du monde, et l'idéologie sociale et humanitaire. Qui ne sont rien d'autre, on le voit, que l'attitude même de l'homme moyen devant la mutation du monde. Mêlant sa voix à celle de la foule, l'unanimisme lançait ses adjurations au monde nouveau. Mais le monde répondit par la guerre; l'événement allait trop vite pour les âmes. L'unanimisme finit dans la prose; ses poètes devinrent des romanciers.

Ce fut la guerre, une première fois, puis une seconde. L'homme, la société furent entraînés au rythme de l'événement échevelé. Les poètes, continuant malgré tout d'exprimer la communauté, chantèrent le désespoir ou la haine, pleurant à l'arrière-garde ou vociférant à l'avant-garde. Comme le dit l'un d'entre eux, Aragon:

Ils contemplaient le grand désastre sans comprendre

D'où venait le fléau ni d'où venait le vent

Et c'est en vain qu'ils interrogeaient les savants

Qui prenaient après coup des mines de Cassandre.

C'est là le premier sens, la signification immédiate de l'aventure de la poésie dans le monde d'aujourd'hui. Avant d'être expérience unique d'un être irremplaçable, le poète, la poésie est d'abord incarnation; non pas seulement, ni surtout, dans la chair même du poète, comme l'ont cru in- 
considérément tant de "grands" de la poésie moderne, mais dans la chair de tous les hommes, dans la société. Comme chacun, le poète n'accède à l'expérience de l'instant privilégié qu'en se dégageant de la société et ce non pas en la refusant, mais en lui donnant un sens. 


\title{
Soljénitsyne ou le salut de l'Histoire ${ }^{1}$
}

\author{
Fernand Dumont
}

Celui qui lit des ouvrages historiques, fussent-ils les plus rigoureux, ajoute entre les lignes et dans les marges. L'autre soir, je feuilletais avec Pierre Perrault le récit où $M$. Jérémie, un vieil auteur du $x_{\text {viII }}^{\mathrm{e}}$ siècle, fait part de ses voyages aux alentours de notre Baie-James. Il y a là de belles pages sur les animaux, sur les Esquimaux et les Indiens. Mais faut-il réduire ce livre à un document de zoologie primaire et d'ethnologie élémentaire? Comment ne pas céder un peu à l'enchantement de la distance et du rapprochement entre $M$. Jérémie et nous. Comment ne pas le suivre en rêve un peu plus loin que ses écrits, lui qui, comme nous l'apprend le bon vieux Dictionnaire de LeJeune, fut un officier d'Iberville. Faudrait-il nous défendre d'écouter, fut-ce en cachette de la science, les cris des matelots, de sentir la poudre des combats douteux, de regarder par personne interposée les glaces de ce temps ancien rejoindre les neiges de François Villon?

L'histoire n'est pas seulement ce qui en reste comme témoignage certain, bien que cette certitude soit une préoccupation qui nous honore. Une fois que nous avons épuisé ce que la science nous explique de l'anonymat des mots et de nos vies, il reste à apprendre autre chose encore: pourquoi il ne nous suffit pas d'être les contemporains de nous-mêmes, pourquoi nous avons besoin de nous reconnaître par des détours dans le passé.

Dans le fond, ce qui fait défaut à la science historique, et par des exigences de démarches que je ne conteste pas le moins du monde, c'est la possibilité d'inventer des personnages ou de prêter à des êtres réels du passé des pensées et des conduites qu'aucun document ne peut garantir.

Cela est privilège du roman. Le roman est l'achèvement de l'histoire puisque, au lieu de recenser des êtres et des événements dits réels, il crée des êtres et des événements historiquement possibles. Nos personnes elles-mêmes apparaissent alors pour ce qu'elles sont: des personnages entre tant d'autres que suggère l'histoire.

Voilà ce que je me suis répété souvent à la lecture d'Août 14 de Soljénitsyne. Il n'est pas de plus belle démonstration que le roman achève en

1. Publié originalement dans Le Devoir, samedi 27 janvier 1973, p. 13. 
quelque sorte le travail de l'historien. Je ne serais pas surpris que l'auteur l'ait vu ainsi puisqu'il a commencé par dépouiller patiemment les livres et les documents qui concernent cette période.

Je savais que l'armée russe avait envahi la Prusse orientale dès les débuts de la première guerre mondiale. Je savais un peu l'état pitoyable de cette armée, sa mauvaise organisation, la bêtise de tant d'officiers de cours et de salon. Je savais que le tsarisme courait à sa perte prochaine. Je savais, je savais... Je ne savais rien. Je n'avais pas entendu bavarder ces paysans venus de leurs villages et rassemblés pour la première fois dans la conscience d'un même pays et de ses malheurs. Je n'avais pas réalisé que des gens de gauche de ce temps-là parlaient aussi abstraitement que certains individus qui nous entourent... sous prétexte d'être concrets. Je n'avais pas suivi le vieux général en chef par les chemins de son angoisse. Je n'avais pas reconnu dans cette déroute d'une armée celle de toutes nos sociétés. Je n'avais pas rencontré le Colonel Vorotyntsev.

Une histoire de guerre où rien n'est épargné dans la description des mouvements de troupe, les débats des États-majors, les récits de bataille. La guerre seule met ensemble les sociétés et, par conséquent, l'histoire. On peut le regretter, mais c'est ainsi. La politique ne rassemble souvent qu'en laissant chacun à sa place. Sur ce fond de guerre, les individus ressortent dans la singularité de leur destin. Les hommes meurent, et par épisodes successifs, en ce mois d'août. Ils sont héroïques ou lâches. Ils pillent, se réjouissent ou se désespèrent. Ils se souviennent de leurs villages, de leurs amours ou de leurs idées. Mais, par dessus tout, ils montrent que l'histoire ne se révèle que parce qu'on en discute.

Alors montent en surface toutes les raisons, comme les écumes aux heures de ressac.

Le général en chef Samsonov avait tant de fois refait des plans et méprisé les officiers courtisans que, ce jour-là, il dut chercher une stratégie qui concernât son âme elle-même. Au soir de la plus grande incertitude, il s'agenouille devant les icônes qu'il a apportées:

"D'abord, ce furent deux ou trois prières connues... Puis (la prière) continuait sans paroles, tout en nuages de fumée et dans la brume, sautant d'une strate à l'autre, ces strates ébranlées comme les blocs de glace au jour où elle se brise... Et si le Seigneur condescendait à intervenir dans la bataille comme, à en croire les légendes, c'était arrivé plus d'une fois dans les temps passés.... Il finira par se suicider, le général Samsonov. Sans perdre son âme, car jamais il ne l'aura autant portée avec lui.

Le colonel Vorotyntsev a étudié à l'étranger, il a participé à d'autres guerres. Un expert, mais qui court les routes. Il lui reste des sentiments, des raisons aussi et il passera sa vie à les composer. Il s'acharne à planifier, même quand il n'en est plus temps, même quand il faut s'adresser au conseil de son altesse impériale et en être chassé ensuite. 
Et voici Obodowski, le technocrate qui fait des conférences pendant que les autres font la guerre. Lui aussi a étudié à l'étranger. Il se trouve confronté à un auditoire où se mêlent des hommes d'affaires et des anarchistes. Il voudrait manger tranquille entre deux colloques, mais il faut bien répondre aux questions comme un conférencier qui se respecte. La réponse est destinée à un jeune: "À nos soirées d'étudiants, à la fin du siècle dernier, déjà le schisme se marquait: d'un côté les ingénieurs, d'un côté les révolutionnaires, bâtir ou détruire... Quiconque a œuvré de ses propres mains, celui-là sait qu'il n'existe qu'une seule production qui n'est ni capitaliste, ni socialiste: celle qui produit la richesse nationale, la base matérielle commune, sans laquelle pas un seul peuple ne saurait survivre."

L'étudiant Kostia fait ailleurs contrepoids. C'est un marxiste qui cherche passionnément à dépassionner la révolution. Il veut "définir le peuple d'une façon rigoureusement scientifique..." L'intelligentsia aussi. Et que sais-je encore.

La galerie n'est pas complète. Car les personnages et les discussions foisonnent dans ce gros livre qui est un monde. Celui de la vieille Russie morcelée, somptueuse de paysages, de traditions et de paroles et que cette guerre enlise, comme ses armées perdues dans le froid et la boue, les détours des lacs et les prétentieuses incertitudes de ses chefs. Mais il s'agit bien plus que de la Russie. De n'importe quel pays, du nôtre, si l'on veut. Ce sont toutes les patries qui vivent et s'interrogent dans ce roman. C'est surtout l'histoire telle qu'elle se fait ici ou ailleurs. Car c'est bien elle, en définitive, qui rêve et se cherche en août 14 .

Tout au fond, que pense donc Soljénitsyne de l'histoire? Il est difficile de le dire puisque nous sommes devant une dramatique et non pas devant un théorème. C'est là peut-être l'essentiel et que seul le roman pouvait nous suggérer: que justement l'histoire n'est pas une théorie. Soljénitsyne le confesse sans doute au mieux par la voix du vieux savant Varsonofiev qui, attablé à la taverne devant deux étudiants, déclare après avoir essuyé la bière de ses moustaches: "L'histoire croît comme un arbre vivant. Et la raison, pour elle, c'est une hache; ce n'est pas avec la raison que vous la ferez pousser. Ou, si vous voulez, l'histoire est un fleuve, elle a ses lois qui en régissent le cours, les méandres, les tourbillons. Mais il y a des malins qui viennent vous dire qu'elle n'est qu'un étang croupissant, qu'il faut la transvaser dans un autre lit, meilleur, qu'il suffit de bien choisir l'endroit où on va creuser le chenal. Mais le fleuve, son courant, on ne peut pas l'interrompre, il suffit d'un pouce d'écart et c'en est fini du courant. Et on nous propose d'y faire une déchirure de dix mille pieds. La continuité des générations, des institutions, des traditions, des habitudes — voilà ce qui fait l'unité du courant."

Ce n'est pas encore le dernier mot sur l'histoire et sur la façon de vivre avec elle. 
Un petit groupe d'hommes entraînés par la défaite tente de trouver passage malgré l'étau des armées allemandes qui se referme sur les russes en retraite. Les soldats transportent le cadavre de leur colonel qu'ils ne veulent point abandonner en terre étrangère. Sacha, le révolutionnaire, en a assez de ces simagrées: "À quoi bon porter un mort? Nous ne sommes pas des sauvages." Et puis, dit-il à Vorotyntsev, vous me demanderez aussi de porter le lieutenant qui doit être un ultra-réactionnaire.

sur de l'eau."

- "Les désaccords politiques, monsieur l'enseigne, ce sont des rides

Sacha la trouve bien bonne:

- "Dans ce cas, que direz-vous des désaccords entre nations? C'est aussi une ride sur l'eau? C'est pourtant à cause d'eux que nous combattons? Quelles sortes de désaccords sont essentiels, alors?"

— "Entre honneur et déshonneur", dit Vorotyntsev.

L'honneur: le grand mot qu'il ne faut sans doute lâcher qu'après avoir épuisé les analyses mais qui alors est le dernier sens que l'on puisse donner à l'histoire. Ce n'est pas par hasard que le mot est prononcé parmi ces hommes qui veulent, de la défaite la plus grande, sauver un mort.

Mais les morts sont-ils tout à fait dans l'éternité ou dans le néant, selon nos croyances diverses? Peut-être ne sommes-nous pas simplement la suite de leurs décisions et de leurs actes. Ont-ils besoin de nous pour être morts, avons-nous besoin d'eux pour être vivants? Ont-ils un avenir parce que nous nous soucions de leur histoire? Sommes-nous des vivants parce que nous les faisons revivre?

Ces questions étranges nous accompagneront dorénavant. Depuis que, grâce à Soljénitsyne, nous avons, nous aussi, rallié le pauvre cortège qui tente de retrouver désespérément quelque patrie perdue. 